\title{
Оценка влияния валютного риска на стоимость компании
}

\author{
Бобровская М.С. ${ }^{19}$
}

В статье представлено сравнение существующих подходов к учету воздействия валютного риска на стоимость компании, рассчитываемую методом дисконтированных денежных потоков (модель DCF). Обосновывается предпочтительность подхода, который заключается в оценке подверженных валютному риску денежных потоков исходя из прогнозных валютных курсов. Указанный способ учета валютного риска в оценке стоимости компании продемонстрирован на основе метода имитационного моделирования.

\section{$J E L: G 32$}

Ключевые слова: стоимость компании, валютный риск, ставка дисконтирования, денежные потоки, форвардные валютные курсы

После распада Бреттон-Вудской системы фиксированных обменных курсов в 70-е годы $\mathrm{XX}$ века в международной экономике наблюдаются значительные колебания не только номинальных, но и реальных обменных курсов, что приводит к отклонениям в соотношении валют от паритета покупательной способности. Финансовый кризис 2008-2009 годов, рост дефицита бюджета и государственного долга стран - членов Евросоюза, природные катаклизмы в Японии и Таиланде значительно обострили проблему волатильности валютных курсов в последнее время. В таких условиях несбалансированность активов и пассивов компаний, вовлеченных в международную деятельность, а также денежных потоков в иностранной валюте приводит к отклонениям результатов деятельности компаний от ожидаемых показателей вследствие курсовых колебаний, т.е. делает их подверженными валютному риску.

С середины 70-х годов XX века в связи с активизацией процессов глобализации хозяйственной деятельности в экономической науке стали проводиться исследования в отношении подверженности стоимости компаний валютному риску. С пионерной работы А. Шапиро «Изменения валютных курсов, инфляция и стоимость международной корпорации» (Shapiro, 1975) начинает разрабатываться гипотеза о том, что стоимость компаний, осуществляющих экспортные продажи и вовлеченных в международную конкуренцию, подвержена валютному риску. Степень этой подверженности зависит от доли продукции, идущей на экспорт, от уровня конкуренции с иностранными компаниями и от возможности замещения зарубежных факторов производства внутренними.

P. Дорнбуш и С. Фишер (Dornbusch and Fischer, 1980) выдвинули гипотезу о том, что изменения валютного курса влияют на конкурентные позиции международной компании и, следовательно, на прибыль и цену акций. Обесценение национальной валюты удешевляет экспортные товары и ведет к росту спроса за рубежом и продаж, в результате чего растут денежные потоки компании. Следовательно, стоимость экспортирующей фирмы вырастет благодаря обесценению национальной валюты. С другой стороны, если спрос иностранцев на продукцию экспортирующей фирмы упадет в связи с укреплением национальной валюты, прибыль и стоимость акций также снизятся. Чувствительность прибыли к валютному курсу импортирующих фирм прямо противоположная: укрепление (обесценение) национальной валюты ведет к росту (падению) стоимости компании. С другой стороны, как отмечают Р. Дорнбуш и С. Фишер, валютный курс оказывает влияние на рыночную стоимость компании

\footnotetext{
${ }^{19}$ Аспирантка кафедры «Финансы и кредит» экономического факультета МГУ им. М.В. Ломоносова, старший консультант ЗАО «БДО».
} 
через приток/отток капитала. Если национальная валюта обесценивается, внутренние активы, в том числе и акции, выраженные в национальной валюте, становятся дешевле для иностранцев. Следовательно, снижение курса внутренней валюты ведет к росту спроса на акции компаний и, таким образом, повышает их стоимость.

Для целей количественной оценки подверженности стоимости компании валютному риску в рамках данной статьи выделены возможные методологические подходы к учету влияния валютного риска на стоимость компаний и обоснована предпочтительность подхода, который заключается в оценке подверженных валютному риску денежных потоков исходя из прогнозных валютных курсов.

\section{Учет валютного риска при оценке стоимости компании методом DCF}

Модель оценки стоимости компании DCF (discounted cash flow) основывается на принципе, что покупатель заплатит за компанию не больше той суммы доходов, которые она будет приносить в будущем. Для целей оценки стоимости компании методом DCF рассчитываются денежные потоки предприятия, т.е. доходы, которые могут быть получены собственниками и кредиторами от инвестирования в данный бизнес. Показатель денежного потока каждого прогнозного периода определяется на основе информации о прошлых результатах бизнеса, перспектив его развития, отраслевой и общеэкономической информации, а также методов экономического анализа, статистики и математического моделирования. Данные потоки приводятся к текущей стоимости на момент оценки путем дисконтирования их по ставке, которая учитывает альтернативные возможности инвестирования, а также факторы риска.

Соответственно, при оценке стоимости компании специфические особенности ее бизнеса могут быть отражены либо в денежном потоке, либо в ставке дисконтирования. В связи с этим в экономической науке были выработаны два альтернативных способа учета влияния валютного риска на стоимость компании:

- учет валютного риска в ставке дисконтирования или

- учет валютного риска в денежных потоках.

\section{Учет валютного риска в ставке дисконтирования}

Первый подход к оценке влияния валютного курса на стоимость компании отходит от концептуальной основы модели САРМ о включении в требуемую доходность только недиверсифицируемых рисков в пользу «полного учета рисков» для целей определения ставки дисконтирования в модели DCF.

Впервые модификацию САРМ с учетом валютного риска предложил Б. Солник (Solnik, 1983) в 1983 году. В нее им была добавлена премия за валютный риск - аналог рыночной премии за риск, а также фактор чувствительности актива $i$ к валютам $1 \ldots k-$ аналог меры систематического риска - коэффициента $\beta$.

Классическим же подходом к определению степени подверженности стоимости компании валютному риску считается метод, предложенный М. Адлером и Б. Дюма (Adler and Dumas, 1984). Подверженность валютному риску определяется как коэффициент линейной регрессионной зависимости стоимости компании от валютного курса:

$$
\begin{gathered}
\mathrm{P}=\mathrm{a}+\mathrm{b} * \mathrm{~S}+\mathrm{e}, \\
\mathrm{a}=\overline{\mathrm{P}}-\mathrm{b} * \overline{\mathrm{s}}, \\
\mathrm{b}=\operatorname{cov}(\mathrm{P}, \mathrm{s}) / \operatorname{Var}(\mathrm{s}),
\end{gathered}
$$

где:

$\mathrm{P}$ - цена актива в иностранной валюте,

$\mathrm{S}$ - курс иностранной валюты.

На основе модели М. Адлера и Б. Дюма было проведено множество эмпирических 
исследований, в которых временные ряды рассматривались как набор различных состояний стоимости компании и курсов валют, и строились регрессии зависимости стоимости акций компаний от валютных курсов.

В результате в одних эмпирических исследованиях (Smith, 1992; Phylaktis and Ravazzolo, 2000; Granger et al., 2000; Abdalla and Murinde, 1997) была обнаружена положительная зависимость между рыночными доходностями акций и колебаниями валютного курса. В других работах (Soenen and Hennigar, 1988; Ajayi and Mougoue, 1996; Ma and Kao, 1990) связь между аналогичными показателями для других компаний и других временных интервалов оказалась отрицательной. В третьей группе исследований (Bartov and Bodnar, 1994; Dominguez and Tesar, 2006; Bodnar and Gentry, 1993) связи не было выявлено вообще.

В работах уделялось внимание стоимости японских частных компаний (He and $\mathrm{Ng}$, 1998), автоконцернов (Williamson, 2001); подверженности стоимости индивидуальных компаний валютному риску в зависимости от хеджирующих стратегий (Allayannis, Ihrig, and Weston, 2001); асимметричной подверженности снижению и укреплению курса (Koutmos and Martin, 2003); подверженности стоимости компаний валютному риску в течение различных временных горизонтов (Bartov and Bodnar, 1994). В целом в данных исследованиях с высокой долей достоверности была подтверждена гипотеза о большей подверженности валютному риску компаний, занимающихся экспортными операциями.

T. Гао $(\mathrm{Gao}, 2000)$ утверждает, что валютный риск элиминируется дальновидными инвесторами и менеджерами, и предлагает исследовать лишь резкие скачкообразные колебания. Подверженность стоимости компаний валютным рискам наиболее заметно проявляется в периоды резких валютных колебаний, происходящих во время финансовых кризисов или смены государственной валютной политики.

Так, А. Муллер и В.Ф. Версчур (Muller and Verschoor, 2009) исследовали волатильность цен на акции американских компаний, которые имели подразделения в развивающихся странах, в периоды недавних финансовых кризисов: мексиканский кризис в декабре 1994 года, финансовый кризис в Аргентине в марте 1994 года, кризис 1999 года в Бразилии и кризис 1997 года в азиатских странах. Все они сопровождались значительным обесценением национальных валют. Акцент на данных кризисных этапах позволил авторам выявить более высокую реакцию акций американских компаний, осуществлявших деятельность в вышеуказанных регионах, на валютные колебания по сравнению с аналогичными компаниями (одинаковая отрасль, сопоставимые размеры), не имеющими подразделений в этих странах. При этом, по мнению А. Муллера и В.Ф. Версчура, в период кризиса мера риска стоимости собственного капитала - коэффициент $\beta$ - значительно вырастает в связи с ростом волатильности валютных курсов.

В работах (Granger et al., 2000; Pan, Fok and Liu, 2007;Choi and Denzau, 2007) авторы рассмотрели подверженность стоимости акций компаний валютному риску за период азиатского кризиса 1997 года. Для большинства стран азиатского региона зависимость доходности акций расположенных там компаний от изменений валютного курса оказалась существенной. В работе Лин Чен-Цю (Lin Chien-Hsiu, 2012) исследовался как азиатский кризис 1997 года, так и последний мировой финансовый кризис 2008-2009 годов. Автор выявил наличие более значительной зависимости между колебаниями валютных курсов и стоимостью компаний в периоды кризисов по сравнению с периодами экономической стабильности. П.Ф. Диамандис и А.А. Дракос (Diamandis and Drakos, 2011) исследовали долгосрочную связь между валютными курсами и ценами акций компаний Латинской Америки. Ими было доказано наличие такой долгосрочной связи, однако уровень этой связи изменялся в результате кризисов: мексиканского кризиса 1994 года и мирового кризиса 2008-2009 годов.

Однако многим исследователям не удалось обнаружить значимую связь между доходностью акций компании и волатильностью валютного курса. Например, К. Девентер, Р. Хиггинс и Т. Симин (Dewenter, Higgins and Simin, 2005) обнаружили, что во время падения 
песо в 1993 и в 1997 годах (во время кризиса таиландского бата) компании проявляли слабую подверженность валютным колебаниям.

Данный факт в зарубежной экономической литературе был определен термином «exposure puzzle». В работе П. Джориона (Jorion, 1990) было выявлено, что лишь у 5\% компаний США доходность акций подвержена колебаниям валютных курсов. Автор предположил, что подверженность валютному риску меняется с течением времени вместе с изменением вовлеченности компании в международные операции. Поэтому показатель валютного риска в модели М. Адлера и Б. Дюма (Adler and Dumas, 1984) - бетакоэффициент - при индексе колебаний обменных курсов должен быть рассмотрен в зависимости от факторов международной деятельности компании. Е. Бартов и Г. Боднар (Bartov and Bodnar, 1994) объясняют exposure puzzle тем, что в предыдущих работах рассматривалась возможность лишь мгновенного реагирования цен акций на колебания валютного курса, хотя на самом деле, по мнению авторов, эффект можно наблюдать лишь с определенным временным лагом.

В итоге вышеперечисленные варианты модификации модели М. Адлера и Б. Дюма (Adler and Dumas, 1984), исследующие влияние валютного риска на требуемую доходность собственного капитала, решили exposure puzzle лишь отчасти. В основном количество компаний, стоимость которых стала значимо подверженной валютному риску, выросло до 20-25\% выборки.

По мнению автора, подход к учету валютного риска исходя из построенной модели регрессии стоимости компании в зависимости от курсов валют имеет ряд существенных недостатков.

Во-первых, как утверждают А. Стонхилл и Л. Натансон (Stonehill and Nathanson, 1968), в требуемой доходности собственного капитала, используемой для расчета ставки дисконтирования, учитываются исключительно систематические недиверсифицируемые риски. Так как компания способна захеджировать валютный риск или диверсифицировать валютную структуру активов/обязательств, то он не должен быть включен в ставку дисконтирования. Во-вторых, противоречивость и нестабильность полученных в эмпирических исследованиях результатов свидетельствует о недостаточно чутком восприятии рынком случаев реализации валютных рисков. И наконец, данный подход не в полной мере удовлетворяет потребности менеджеров по управлению валютной позицией компании, так как не позволяет выделить подверженные риску элементы и определить уровень максимальных потерь. Таким образом, становится понятен вывод К. Фрута (Froot, 1994), который говорит: «Я бы хотел отметить, что данный метод (учет валютного риска на основе исторических рыночных котировок) - будучи ни плохим, ни хорошим для анализа подверженности риску - не может и не должен использоваться для принятия стратегий по хеджированию. Компаниям следует анализировать свой риск, исходя из денежных потоков и инвестиционных возможностей».

\section{Учет валютного риска в денежном потоке}

В модели, предложенной А. Стонхилл и Л. Натансон (Stonehill and Nathanson, 1968), влияние валютного риска отражается в величине ожидаемых денежных потоков. Если $d t-$ величина ожидаемого дисконта в связи с изменением курса валюты, то текущая стоимость денежного потока будет равна:

(4)

$$
\operatorname{DCF}_{\mathrm{t}}=\frac{\mathrm{x}_{\mathrm{t}} \times\left(1-\mathrm{d}_{\mathrm{t}}\right)}{(1+\mathrm{k})^{\mathrm{t}}}
$$

Этот метод подходит только тогда, когда денежные потоки в национальной валюте фиксированы и не зависят от валютного курса, например в случае получения процентов по иностранной облигации. Но когда денежные потоки генерируются в рамках действующего бизнеса, денежные потоки в национальной валюте меняются с изменением валютного курса.

Попытка учесть данное обстоятельство сделана в работе А. Шапиро (Shapiro, 1978). Он 
предлагает изолировать различные компоненты прогнозного денежного потока и рассматривать их в отдельности. В результате можно проследить зависимость от валютного риска выручки (доля экспортных доходов), расходов (доля иностранных факторов производства) и амортизации. Также необходимо отделить ту выручку и те расходы, которые зафиксированы в контрактах (в национальной или иностранной валюте) от тех ресурсов и продаж, стоимость которых может корректироваться с учетом валютного курса. Кроме того, в связи с изменением конкурентной позиции может быть пересмотрена необходимость в оборотном капитале.

Предположим, нам необходимо оценить денежные потоки, генерируемые иностранным подразделением оцениваемой компании. Обозначим выручку, расходы и амортизацию в иностранной валюте в период времени $t$ соответственно как $R_{t}, C_{t} u D_{t}$. $W t\left(e_{t}\right)-$ чистое изменение оборотного капитала в иностранной валюте при валютном курсе еt. Следовательно, ожидаемый посленалоговый (ставка налога иностранного государства) денежный поток в валюте материнской компании будет равен:

$$
\left(1-t_{t}\right) *\left[R_{t}\left(e_{t}\right)-C_{t}\left(e_{t}\right)\right] * e_{t}+D_{t} * e_{t}+W t\left(e_{t}\right) * e_{t}
$$

При выборе наиболее предпочтительного подхода для учета валютного риска в стоимости компании автор данной статьи предлагает исходить из следующего. Для целей оценки стоимости компании денежные потоки, генерируемые в иностранной валюте, должны быть переведены в валюту оценки либо по форвардным курсам, либо по курсу «спот» на момент оценки. В зависимости от выбора способа пересчета денежных потоков в иностранной валюте будет различаться и ставка дисконтирования. Дисконтирование денежных потоков в иностранной валюте некорректно осуществлять по ставке средневзвешенных затрат на капитал (WACC), характерной для всей компании, необходимо определить ставку дисконтирования, отражающую риск именно этих денежных потоков. В случае же конвертации денежных потоков из иностранной валюты в функциональную валюту компании по форвардным курсам, риск, присущий пересчитанным денежным потокам, будет аналогичен риску всей компании.

Как отмечают Коупленд и др. (Коупленд и др., 2008), «риски, связанные с валютными курсами или зарубежными инвестициями, хорошо «улавливает» курс «спот». Соответственно, по мнению авторов, обычная конвертация стоимости приведенных денежных потоков в иностранной валюте по курсу на дату оценки позволяет учесть присущие компании валютные риски. В то же время расчет отдельной ставки дисконтирования, соответствующей каждому денежному потоку в иностранной валюте, представляется достаточно затруднительным. Кроме того, курс «спот» в большей степени отражает текущее равновесие на валютном рынке и, будучи известной величиной, не может позволить определить степень подверженности компании валютному риску.

По мнению автора, наиболее предпочтительным способом учета влияния валютного риска в оценке стоимости компании выступает расчет ожидаемых денежных потоков с учетом конвертирования всех компонентов по прогнозным курсам в национальную валюту (форвардный метод). Аналогичный способ учета валютного риска предлагает Д. Лессард (Lessard, 1996): валютный риск учитывается в оценке стоимости компании путем пересчета денежных потоков по прогнозным валютным курсам. При этом Д. Лессард предлагает использовать дискретные прогнозные значения валютных курсов.

Данный подход, в отличие от учета валютного риска в ставке дисконтирования, является более корректным, так как валютный риск компании, по мнению ряда экономистов - А. Стонхилл и Л. Натансон (Stonehill and Nathanson, 1968), А. Шапиро (Shapiro, 1978) следует считать диверсифицируемым, в связи с тем что компания может изменять степень подверженности валютному риску путем осуществления операций хеджирования, а также диверсифицируя валютные структуры активов/обязательств. Также валютный риск присущ не всем денежным потокам компании, по крайней мере, не в равной степени, поэтому простая надбавка к ставке дисконтирования также будет неправомерной с методологической точки зрения. 
Кроме того, данный подход, в отличие от корректировки денежных потоков, предложенной А. Стонхиллом и Л. Натансоном, а также метода «спот», позволяет учитывать двустороннее колебание курсов валют, т.е. возможность получения неожиданных потерь наравне с убытками.

И наконец, форвардный метод позволяет дать количественную оценку подверженности стоимости компании валютному риску подобно методу Value-at-Risk (VaR), рекомендованному Базельским комитетом в качестве метода оценки риска колебаний стоимости позиций банков в иностранной валюте, что является удобным инструментом для стресс-тестирования, оперативной корректировки модели оценки и принятия менеджерами управленческих решений.

С другой стороны, прогнозирование форвардных валютных курсов в условиях нестабильной экономической обстановки, смены политического курса может не давать адекватную и надежную оценку, как, впрочем, и прогнозирование иных параметров модели оценки - объемов реализуемой продукции, цен, налогов и др.

\section{Демонстрация учета валютного риска в денежных потоках при помощи имитационного моделирования на гипотетическом примере}

Оценка стоимости компании с учетом рисков в денежных потоках отражает очевидный, но важный принцип: полученное значение стоимости в условиях неопределенности не является конкретным числом, а будет варьироваться в зависимости от волатильности внутренних и внешних факторов.

Универсальным методом, позволяющим оценить волатильность стоимости компании в условиях неопределенности, является имитационное моделирование с использованием современных программных продуктов (например, Oracle Crystal Ball). Имитационное моделирование является многоэтапным процессом. Сначала необходимо выявить входные данные модели (объем продаж, цены, затраты и др.), установить взаимосвязь между входными параметрами и величинами, ожидаемыми на выходе модели. Затем нужно задать законы распределения ключевых параметров и их корреляцию между собой в компьютерной программе, после чего провести ряд компьютерных симуляций и получить выходные показатели. На основе полученных результатов можно провести анализ подверженности величины выходных значений модели риску изменений исходных параметров.

Для демонстрации способа учета валютного риска в оценке стоимости компании рассмотрим гипотетический пример компании $\mathrm{ABC}$ до и после вовлечения в международную деятельность. Изначально компания АВС реализовывала свою продукцию исключительно в России. Затем, оценив перспективы зарубежных рынков сбыта, компания АВС стала рассматривать возможность экспорта своей продукции в США. В то же время реализация продукции в США возможна только в долларах США, в результате чего компании АВС необходимо будет конвертировать полученную выручку в рубли для покрытия местных расходов.

Детали расчета стоимости компании АBC методом DCF до принятия решения о направлении части производимой продукции на экспорт представлены в таблице 1.

Таблица 1

Оценка стоимости компании АВС при реализации продукции в России

\begin{tabular}{|c|c|c|c|c|c|}
\hline Показатели & \begin{tabular}{|c|} 
Единицы \\
измерения \\
\end{tabular} & 2011П* & 2012П & 2013П & 2014П \\
\hline 1 & 2 & 3 & 4 & 5 & 6 \\
\hline Объем продаж & Шт. & 3502 & 3700 & 4100 & 5000 \\
\hline Цена за ед. & тыс. руб. & 10 & 11 & 12 & 12,5 \\
\hline Выручка & тыс. руб. & 35020 & 40700 & 49200 & 62500 \\
\hline Операционные & тыс. руб. & 19260 & 21920 & 25620 & 35080 \\
\hline
\end{tabular}




\begin{tabular}{|c|c|c|c|c|c|}
\hline затраты & & & & & \\
\hline EBITDA & тыс. руб. & 15760 & 18780 & 23580 & 27420 \\
\hline Амортизация & тыс. руб. & 2240 & 2700 & 3120 & 3360 \\
\hline EBIT & тыс. руб. & 13520 & 16080 & 20460 & 24060 \\
\hline $\begin{array}{l}\text { Процентные } \\
\text { расходы }\end{array}$ & тыс. руб. & 550 & 630 & 715 & 740 \\
\hline EBT & тыс. руб. & 12970 & 15450 & 19745 & 23320 \\
\hline $\begin{array}{l}\text { Минус: Налог на } \\
\text { прибыль }\end{array}$ & тыс. руб. & 2594 & 3090 & 3949 & 4664 \\
\hline $\begin{array}{l}\text { Минус: } \\
\text { Капитальные } \\
\text { вложения }\end{array}$ & тыс. руб. & 11700 & 8840 & 4560 & 730 \\
\hline $\begin{array}{l}\text { Минус: } \\
\text { Изменение } \\
\text { рабочего } \\
\text { капитала } \\
\end{array}$ & тыс. руб. & 760 & 640 & 300 & - \\
\hline $\begin{array}{l}\text { Плюс: } \\
\text { Амортизация }\end{array}$ & тыс. руб. & 2240 & 2700 & 3120 & 3360 \\
\hline $\begin{array}{l}\text { Плюс: Проценты } \\
\text { по кредитам с } \\
\text { учетом налога }\end{array}$ & тыс. руб. & 440 & 504 & 572 & 592 \\
\hline $\begin{array}{l}\text { Свободный } \\
\text { денежный поток }\end{array}$ & тыс. руб. & 2116 & 7364 & 15228 & 21878 \\
\hline $\begin{array}{l}\text { Коэффициент } \\
\text { дисконтирования } \\
\text { (WACC) } \\
\end{array}$ & тыс. руб. & 1 & 1,118 & 1,250 & 1,397 \\
\hline $\begin{array}{ll}\mathrm{PV} & \text { будущего } \\
\text { FCFF } & \\
\end{array}$ & тыс. руб. & 2116 & 6587 & 12183 & 15656 \\
\hline $\begin{array}{l}\text { Продленная } \\
\text { стоимость }\end{array}$ & тыс. руб. & & & & 208747 \\
\hline $\begin{array}{l}\text { Стоимость } \\
\text { компании } \\
\end{array}$ & тыс. руб. & & & & 245289 \\
\hline
\end{tabular}

* Прогнозные значения.

В соответствии со «Сценарными условиями для формирования вариантов социальноэкономического развития в 2012-2014 гг.» (письмо Минэкономразвития России от 25.04.2011 № 8387-АК/Д03) компания АВС предполагает, что среднегодовой курс доллара США будет изменяться в 2012-2014 годах в соответствии со сценариями, представленными в таблице 2.

Таблица 2

Сценарии изменения среднегодового курса доллара США

\begin{tabular}{|c|c|c|c|c|}
\hline Сценарии & $\mathbf{2 0 1 1}$ & $\mathbf{2 0 1 2}$ & $\mathbf{2 0 1 3}$ & $\mathbf{2 0 1 4}$ \\
\hline $\mathbf{1}$ & $\mathbf{2}$ & $\mathbf{3}$ & $\mathbf{4}$ & $\mathbf{5}$ \\
\hline $\mathrm{cc}$ & 28,30 & 26,80 & 25,60 & 25,00 \\
\hline $\mathrm{2b}$ & 29,00 & 27,90 & 27,90 & 28,00 \\
\hline $1 \mathrm{a}$ & 31,00 & 33,80 & 35,80 & 35,80 \\
\hline
\end{tabular}

Следует отметить, что прогноз Минэкономразвития России не отражает реальные ожидания рынка относительно изменения курса доллара США к рублю. Более корректной мерой оценки в данном случае могли бы служить средние цены по заключаемым 
форвардным контрактам на покупку-продажу долларов США с датами исполнения в соответствующие периоды. В то же время рассмотрение подходов к прогнозированию валютных курсов не является задачей данной статьи, поэтому для целей демонстрационного примера взяты прогнозные значения, предложенные Минэкономразвития России.

Компания АВС предполагает, что стоимость единицы ее продукции в США будет определяться в зависимости от макроэкономических условий, но в целом не будет существенно отклоняться от прогнозных вариантов, представленных в таблице 3.

Таблица 3

Цена продукции в долларах США

\begin{tabular}{|l|c|c|c|c|}
\hline \multicolumn{1}{|c|}{ Сценарии } & $\mathbf{2 0 1 1}$ & $\mathbf{2 0 1 2}$ & $\mathbf{2 0 1 3}$ & $\mathbf{2 0 1 4}$ \\
\hline $\mathbf{1}$ & $\mathbf{2}$ & $\mathbf{3}$ & $\mathbf{4}$ & $\mathbf{5}$ \\
\hline Минимальная цена, тыс. долл. США & 0,30 & 0,34 & 0,37 & 0,37 \\
\hline $\begin{array}{l}\text { Наиболее вероятная цена, тыс. долл. } \\
\text { США }\end{array}$ & 0,35 & 0,40 & 0,44 & 0,45 \\
\hline Максимальная цена, тыс. долл. США & 0,40 & 0,46 & 0,51 & 0,53 \\
\hline
\end{tabular}

Исходя из наиболее вероятных предпосылок относительно цены и курса доллара США, компания $\mathrm{ABC}$ предполагает распределить продажи своей продукции в России и в США так, как показано в таблице 4 , в результате чего ожидает роста стоимости своих акций.

Таблица 4

Оценка стоимости компании АВС при реализации продукции в России и в США

\begin{tabular}{|c|c|c|c|c|c|}
\hline Показатели & $\begin{array}{c}\text { Единицы } \\
\text { измерения }\end{array}$ & 2011П* & 2012П & 2013П & 2014П \\
\hline 1 & 2 & 3 & 4 & 5 & 6 \\
\hline Объем продаж в России & шт. & 2002 & 2000 & 2200 & 2800 \\
\hline Цена за ед. & тыс. руб. & 10 & 11 & 12 & 12,5 \\
\hline Объем продаж в США & ШТ. & 1500 & 1700 & 1900 & 2200 \\
\hline Цена за ед. & $\begin{array}{ll}\text { тыс. } & \text { долл. } \\
\text { США } & \end{array}$ & $\mathbf{0 , 3 5}$ & $\mathbf{0 , 4 0}$ & 0,44 & 0,45 \\
\hline $\begin{array}{l}\text { Среднегодовой } \\
\text { долл. США }\end{array}$ & & 29,00 & 27,90 & 27,90 & 28,00 \\
\hline Выручка, итого & тыс. руб. & 35245 & 40972 & 49724 & 62720 \\
\hline Операционные затраты & тыс. руб. & $-\quad 19260$ & $-\quad 21920$ & $-\quad 25620$ & $-\quad 35080$ \\
\hline EBITDA & тыс. руб. & 15985 & 19052 & 24104 & 27640 \\
\hline Амортизация & тыс. руб. & 2240 & 2700 & 3120 & 3360 \\
\hline EBIT & тыс. руб. & 13745 & 16352 & 20984 & 24280 \\
\hline Процентные расходы & тыс. руб. & 550 & 630 & 715 & 740 \\
\hline EBT & тыс. руб. & 13195 & 15722 & 20269 & 23540 \\
\hline Минус: Налог на прибыль & тыс. руб. & 2661 & 3144 & 4054 & 4708 \\
\hline $\begin{array}{ll}\text { Минус: } & \text { Капитальные } \\
\text { вложения } & \end{array}$ & тыс. руб. & $-\quad 11700$ & 8840 & 4560 & 730 \\
\hline $\begin{array}{l}\text { Минус: } \quad \text { Изменение } \\
\text { рабочего капитала }\end{array}$ & тыс. руб. & 760 & 640 & 300 & - \\
\hline Плюс: Амортизация & тыс. руб. & 2240 & 2700 & 3120 & 3360 \\
\hline $\begin{array}{ll}\text { Плюс: } & \text { Проценты по } \\
\text { кредитам с учетом налога }\end{array}$ & тыс. руб. & 440 & 504 & 572 & 592 \\
\hline $\begin{array}{l}\text { Свободный денежный } \\
\text { поток }\end{array}$ & тыс. руб. & 2274 & 7582 & 15648 & 22054 \\
\hline
\end{tabular}




\begin{tabular}{|l|l|r|r|r|r|}
\hline $\begin{array}{l}\text { Коэффициент } \\
\text { дисконтирования (WACC) }\end{array}$ & тыс. руб. & 1 & 1,118 & 1,250 & 1,397 \\
\hline PV будущего FCFF & тыс. руб. & 2274 & 6781 & 12519 & 15782 \\
\hline Продленная стоимость & тыс. руб. & & & & 210427 \\
\hline Стоимость компании & тыс. руб. & & & & $\mathbf{2 4 7 7 8 3}$ \\
\hline
\end{tabular}

*Прогнозные значения.

На основе метода имитационного моделирования строим прогноз стоимости компании $\mathrm{ABC}$ в случае принятия решения о направлении части продукции на экспорт. Для этого примем следующие предпосылки:

1. Среднегодовой курс доллара США в 2011-2014 годах имеет треугольное распределение с минимальным значением в соответствии со сценарием 2c, максимальным - 1a и наиболее вероятным - $2 \mathrm{~b}$.

2. Коэффициент корреляции между среднегодовым курсом доллара США в 2012 году и курсом 2011 года, курсом доллара США в 2013 году и курсом 2012 года, курсом доллара США в 2014 году и курсом 2013 года равен 0,3.

3. Цена продукции компании АВС в США имеет нормальное распределение с параметрами, соответствующими сценариям, представленным в таблице 3 .

4. Коэффициент корреляции между курсом доллара США и ценой единицы продукции в долларах США равен -0,5 в каждом году.

На основе данных предпосылок были сгенерированы ряды курса доллара США и цены продукции в долларах США для каждого года. Прогнозируемой переменной выступает стоимость компании АВС. По итогам 1000 итераций были получены следующие результаты.

Таблица 5

Статистические характеристики полученной оценки стоимости компании $\mathrm{ABC}$ с учетом совокупного валютного риска

\begin{tabular}{|l|l|}
\hline \multicolumn{1}{|c|}{$\begin{array}{c}\text { Статистические } \\
\text { характеристики }\end{array}$} & \multicolumn{1}{c|}{ Значения } \\
\hline Trials & \multicolumn{1}{c|}{$\mathbf{2}$} \\
\hline Mean & 1000 \\
\hline Median & 265108 \\
\hline Mode & 264965 \\
\hline Standard Deviation & --- \\
\hline Variance & 46815 \\
\hline Skewness & 2191650813 \\
\hline Kurtosis & $-0,0611$ \\
\hline Coeff. of Variability & 3,19 \\
\hline Minimum & 0,1766 \\
\hline Maximum & 68899 \\
\hline Range Width & 417885 \\
\hline Mean Std. Error & 348986 \\
\hline & 1480 \\
\hline
\end{tabular}

Таким образом, ожидаемая стоимость компании $\mathrm{ABC}$ в случае принятия решения о реализации части продукции в США в среднем будет больше, чем в случае отказа от данного решения (265 108 тыс. руб.).

С учетом принятых предпосылок рассчитанная стоимость компании АВС имеет распределение следующего вида. 


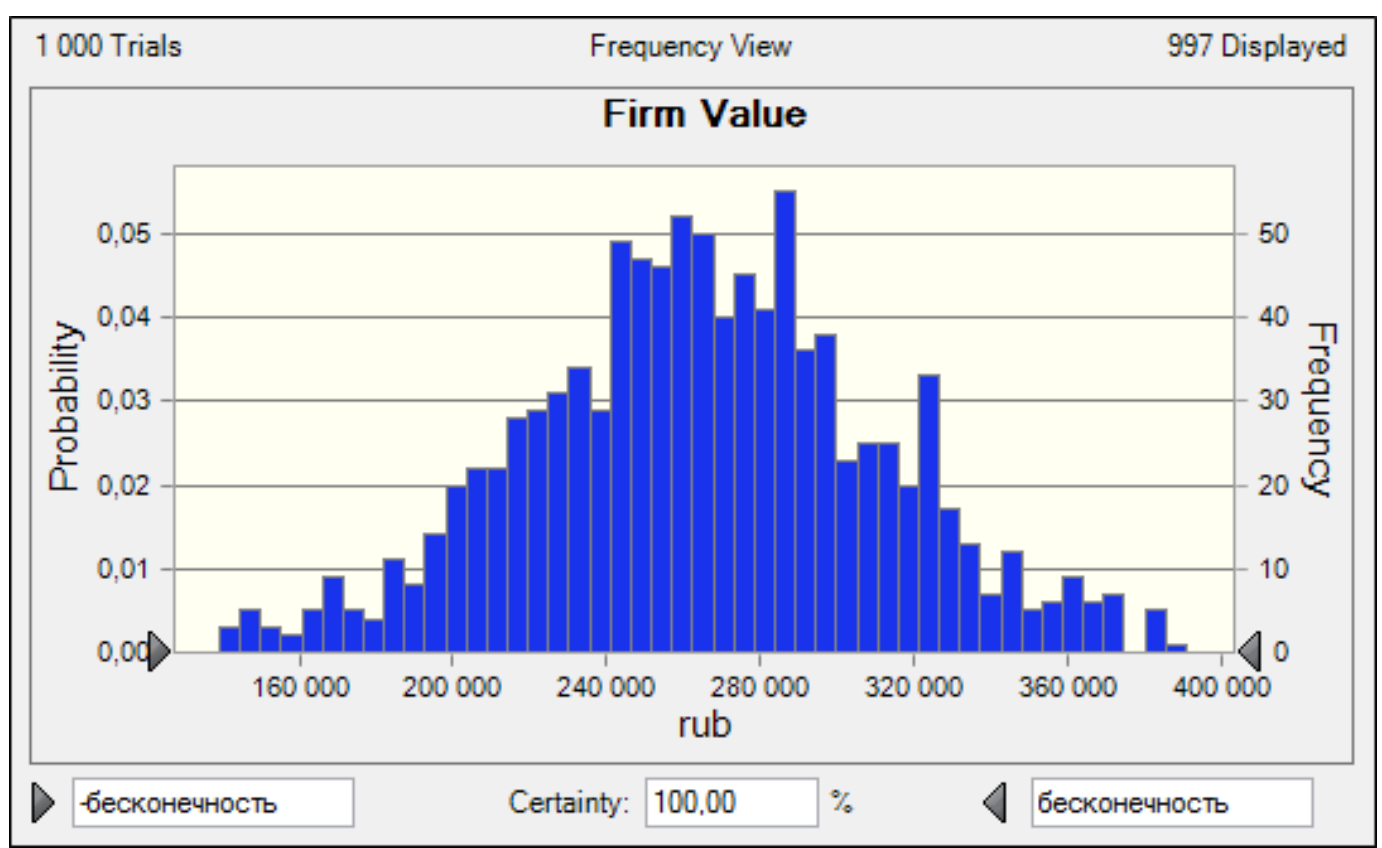

График 1. Стоимость компании АВС с учетом валютного риска

Ниже представлена таблица квантилей, которые выражают процент значений стоимостей, меньших значения в строке напротив. То есть значение 50\%-ной процентили указывает, что 50\% значений располагается ниже его.

Таблица 6

Квантили стоимости компании АВС с учетом валютного риска

\begin{tabular}{|c|c|}
\hline $\begin{array}{c}\text { Вероятность, } \\
\text { \% }\end{array}$ & Квантиль \\
\hline $\mathbf{1}$ & $\mathbf{2}$ \\
\hline 0 & 68899 \\
\hline 10 & 205557 \\
\hline 20 & 226771 \\
\hline 30 & 242647 \\
\hline 40 & 253641 \\
\hline 50 & 264954 \\
\hline 60 & 276502 \\
\hline 70 & 288268 \\
\hline 80 & 302332 \\
\hline 90 & 324881 \\
\hline 100 & 417885 \\
\hline
\end{tabular}

В результате мы можем оценить вероятность того, что стоимость компании АВС в случае принятия решения о переводе части продукции на реализацию в США будет меньше стоимости в случае отказа от таких операций. Как видно из графика 2, такая вероятность составляет больше $30 \%$. Компании АВС необходимо детально проанализировать ее выгоды и риски при выходе на международные рынки и, возможно, пересмотреть масштабы продаж за рубежом, диверсифицировать рынки сбыта, принять решение о хеджировании валютного риска с учетом готовности собственников компании идти на соответствующие риски. 


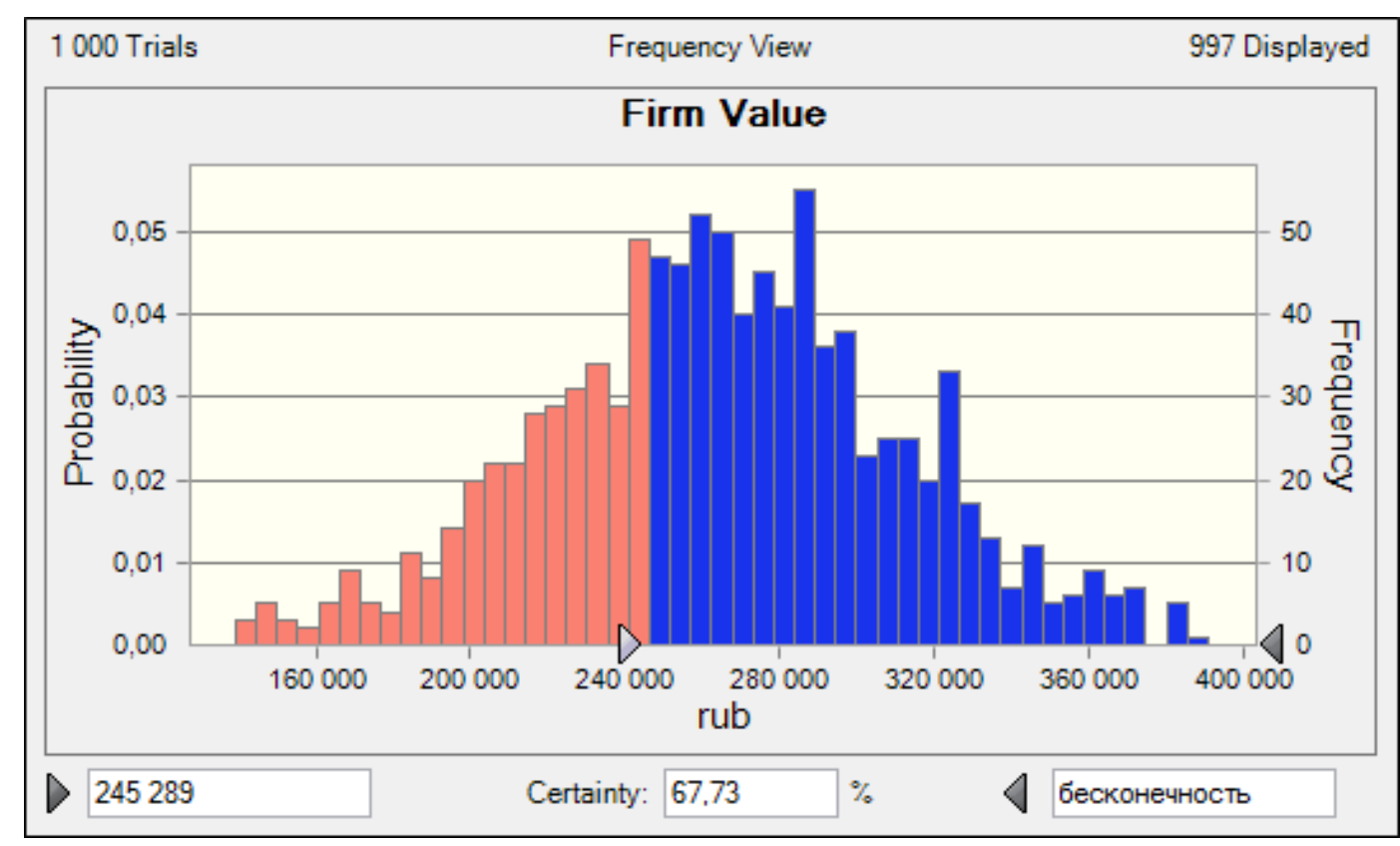

График 2. Риск снижения стоимости компании АВС в случае принятия решения о реализации товаров в США

\section{Выводы}

Волатильность валютного курса в современной экономике является одним из важнейших факторов риска для международного бизнеса. В свою очередь стоимость компании, рассчитываемая дисконтированием денежных потоков, свободных к распределению между всеми инвесторами компании, сосредотачивает в себе полную информацию о деятельности компании, а также о ее подверженности различного рода рискам, в том числе и валютному.

Анализ двух возможных способов учета влияния валютного риска на стоимость компании, а именно учет валютного риска в ставке дисконтирования и учет неопределенности величины валютных курсов в денежных потоках форвардным методом, позволил выявить существенные недостатки первого подхода:

- низкая статистическая значимость коэффициентов регрессионной зависимости доходности акций компаний от валютных курсов в проведенных эмпирических исследованиях, особенно в периоды экономической стабильности;

- степень подверженности компании валютному риску может быть изменена путем диверсификации валютной структуры активов/обязательств, а также в результате хеджирования, что приводит к методологическим противоречиям с концепцией определения требуемой доходности собственного капитала лишь с учетом систематических, недиверсифицируемых рисков;

- валютным рискам подвержены лишь отдельные компоненты денежных потоков, тогда как ставка дисконтирования применяется к совокупному денежному потоку, генерируемому компанией;

- недостаточная пригодность для интерпретации результатов и принятия управленческих решений.

Более методологически верным и удобным с точки зрения риск-менеджмента способом учета валютного риска является оценка подверженных валютному риску денежных потоков с учетом прогнозных валютных курсов, в связи с тем что в прогнозном валютном курсе заложена оценка самого валютного риска.

Подверженность компании валютному риску и алгоритм расчета ее стоимости с учетом волатильности валютных курсов продемонстрированы в статье на гипотетическом примере при помощи метода имитационного моделирования. В примере было показано, что 
неопределенность будущих валютных курсов, учтенная в денежных потоках, приводит к размытой оценке стоимости компании, что вызвано влиянием валютного риска на стоимость компании. Также в статье продемонстрировано, что имитационное моделирование валютных курсов, влияющих на операционные денежные потоки компании, позволяет менеджерам выявлять слабые места в международном бизнесе компании и принимать решения по управлению валютным риском.

\section{Список литературы}

1. Каяшева Е.В., Сытин Ф.М. Оценка, прогноз и управление валютными рисками // Управление финансовыми рисками. 2009. № 2(18). С. 130-142

2. Коупленд Т., Коллер Т., Муррин Дж. Стоимость компаний. Оценка \& управление. М.: Олимп_Бизнес, 2008.

3. Abdalla, I. S. A., and Murinde, V. (1997), Exchange Rate and Stock Price Interactions in Emerging Financial Markets: Evidence on India, Korea, Pakistan, and Philippines, Applied Financial Economics, 7 (1997) 25-35.

4. Adler, M., and Dumas, B. (1984), Exposure to Currency Risk: Definition and Measurement, Financial Management (Financial Management Association), 13(2) (1984) 41-50.

5. Ajayi, R.A., and Mougoue, M. (1996), On the Dynamic Relation between Stock Prices and Exchange Rates, Journal of Financial Research, 19 (1996) 193-207.

6. Allayannis, G., Ihrig, J., and Weston, J.P. (2001), Exchange rate hedging: Financial versus operational strategies, American Economic Review, 91 (2001) 391-395.

7. Bartov, E., and Bodnar, G. (1994), Firm valuation, earnings expectations, and the exchangerate exposure effect, Journal of Finance, 49 (1994) 1755-1785.

8. Bodnar, G., and Gentry, W. (1993), Exchange-rate exposure and industry characteristics: Evidence from Canada, Japan, and the U.S.A., Journal of International Money and Finance, 12 (1993) 29-45.

9. Bodnar, G., and Wong, F. (2003), Estimating exchange rate Exposure: issues in model structure, Financial Management, 32 (2003) 35-67.

10. Choi, J.J. (1986), A model of firm valuation with exchange exposure, Journal of International Business Studies, 2(17) (1986) 153-160.

11. Choi, S., and Denzau, A. (2007), Some Methodological Issues on Estimating Foreign Exchange Exposure of US Multinational Firms: Evidence from the Asian Crisis, Global Economic Review, 36(3) (2007) 217-227.

12. Dewenter, K., Higgins, R., and Simin, T. (2005), Can event study methods solve the currency exposure puzzle, Pacific Basin Finance Journal, 13 (2005) 119-144.

13. Diamandis, P.F., and Drakos, A.A. (2011), Financial liberalization, exchange rates and stock prices: exogenous shocks in four Latin America countries, Journal of Policy Modeling, 33 (2011) 381-394.

14. Dominguez, K., and Tesar, L. (2006), Exchange Rate Exposure, Journal of International Economics, 68 (2006) 188-218.

15. Dornbusch, R., and Fischer, S. (1980), Exchange Rates and the Current Account, American Economic Review, 70(5) (1980) 960-971.

16. Froot, K.A. (1994), Comment on "Exchange Rates and Corporate Strategic Management", Exchange Rates and Corporate Performance, edited by Amihud, Y. and Levich, R.,. New York: New York University, Salomon Center, Irwin. P. 253-256.

17. Gao, T. (2000), Exchange rate movements and the profitability of U.S. multinationals, Journal of International Money and Finance, 19(1) (2000) 117-134.

18. Glaum, M. (1990), Strategic management of exchange rate risks, Long range planning, 23(4) (1990) 65-72.

19. Granger, C.W.J., Huang, B.-N., and Yang C.-W. (2000), A bivariate causality between stock prices and exchange rates: evidence from recent Asian flu, The Quarterly Review of 
Economics and Finance, 40 (2000) 337-354.

20. He, J., and Lilian Ng. (1998), Foreign exchange exposure of Japanese multinational corporations, Journal of Finance, 53 (1998) 733-753.

21. Jorion, P. (1990), The Exchange-Rate Exposure of U.S. Multinationals, Journal of Business, 63 (1990) 331-345.

22. Koutmos, G., and Martin, A.D. (2003), Asymmetric exchange rate exposure: Theory and evidence, Journal of International Money and Finance, 22 (2003) 365-383.

23. Lessard, D.R. (1996), Incorporating Country Risk in the Valuation of Offshore Projects, Journal of Applied Corporate Finance, 9 (1996) 52-63.

24. Lin, C.-H. (2012), The comovement between exchange rates and stock prices in the Asian emerging markets, International Review of Economics and Finance, 22 (2012) 161-172.

25. Ma, C.K., and Kao, G.W. (1990), On Exchange Rate Changes and Stock Price Reactions, Journal of Business Finance \& Accounting, 17(3) (1990) 441-449.

26. Muller, A., and Verschoor, W.F.C. (2009), The effect of exchange rate variability on US shareholder wealth, Journal of Banking and Finance, 33 (2009) 1963-1972.

27. Pan, M.S., Fok, R., and Liu, Y. (2007), Dynamic linkages between exchange rates and stock prices: Evidence from East Asian markets, International Review of Economics and Finance, 16 (2007) 503-520.

28. Phylaktis, K., and Ravazzolo F. (2000), Stock prices and exchange rate dynamics, Mimeo, City University Business School, EFMA Conference, Athens.

29. Pritamani, M.D., Shome, D.K., and Singal, V. (2003), Foreign Exchange Exposure of Exporting and Importing Firms, Journal of Banking and Finance, 28(7) (2003) 1697-1710.

30. Shapiro, A.C. (1975), Exchange rate changes, inflation, and the value of the multinational corporation, Journal of Finance, 30 (1975) 485-502.

31. Shapiro, A. C. (1978), Capital Budgeting for the Multinational Corporation, Financial Management, 17 (1978) 7-16.

32. Soenen, L.A., and Hennigar, E.S. (1988), An Analysis of Exchange Rates and Stock Prices: the U.S. Experience between 1980 and 1986, Akron Business and Economic Review, 19 (4) (1988) 7-16.

33. Solnik, B. (1983), International Arbitrage Pricing Theory, Journal of Finance, 38(2) (1983) 449-457.

34. Smith, C. (1992), Stock Market and the Exchange Rate: A Multi-Country Approach, Journal of Macroeconomics, 14 (1992) 607-629.

35. Stonehill, A., and Nathanson, L. (1968), Capital Budgeting and the multinational corporation, California Management Review, 10 (1968) 39-54.

36. Williamson, R. (2001), Exchange rate exposure and competition: Evidence from the automotive industry, Journal of Financial Economics, 59 (2001) 441-475. 